Western University Scholarship@Western

1984

\title{
Business Cycles with Costly Search and Recruiting
}

Peter Howitt

Follow this and additional works at: https://ir.lib.uwo.ca/economicsresrpt

Part of the Economics Commons

Citation of this paper:

Howitt, Peter. "Business Cycles with Costly Search and Recruiting." Department of Economics Research Reports, 8417. London, ON: Department of Economics, University of Western Ontario (1984). 


\section{RESEARCH REPORT 8417}

BUSINESS CYCLES WITH COSTLY

SEARCH AND RECRUITING

by

Peter Howitt

October, 1984

Depertinent of Econonics Library

\section{OCT 101984}

University of Western Ontario

An earlier version of this paper was originally presented at a conference on macroeconomics at McMaster University in October, 1983. Useful comments and suggestions were received from the participants there, as well as from my colleagues Joel Fried, David Laidler, Preston McAfee, Hans-Werner Sinn, Aman Ullah, and Michael Veall. 
Macroeconomic theories are distinguished to a large extent by their different treatments of labor markets. "New classical" theories, including "real business cycle" theories model them as rapidly clearing auction markets, and seek to explain fluctuations in employment as movements along a supply of labor schedule. Keynesian theories assume that wages are slow to clear labor markets, so that fluctuations in employment are movements off the supply curve.

Both of these approaches have been subject to well-known criticisms. New classical theories require what many regard as an implausibly large elasticity of labor-supply (or of intertemporal substitution of labor) in order to be consistent with the relatively small movements of real wages over the business cycle. They seem to imply anti-cyclical quit rates which are not observed, and they cannot explain the apparently involuntary character of unemployment.

The Keynesian approach has been criticized by Barro (1979) and others for failing to explain clearly why potential gains from trade remain unexploited. The logical underpinning of wage (price)-setting behavior are unclear, but from what we know of them they do not imply that quantities will be demanddetermined as in Keynesian economics. They also seem to imply stickiness of relative prices whereas Keynesian economics postulates stickiness of nominal prices. Furthermore, in order to account for persistent unemployment the Keynesian approach must explain why potential workers without contracts do not succeed in underbidding those with contracts, whereas contract theory assumes that everyone who wants one always has a contract. 
Elsewhere (1984) I have argued that many of the conclusions of Keynesian economics can be derived without having to rely upon sticky wages or prices, by recognizing explicitly the high cost of transacting in some markets, the factor stressed by such writers as Leijonhufvud, Okun, and Laidler, as well as the external economy of scale implicit in the notion that trading is more costly the thinner the market, an idea embodied in several recent contributions of Peter Diamond. Preston MaAfee and I have developed an explicit model of labor markets along these lines with costly job-search and recruiting, in which there exists a continuum of natural rates of unemployment.

The present paper develops a model of the business cycle based upon a simplified version of the Howitt-McAfee model, rather than upon clearing labor markets or sticky wages. One purpose of this model is to suggest by example that this alternative conception of labor markets may permit a business-cycle theory that avoids some of the shortcomings of alternative conceptions. In particular, the model exhibits persistent involuntary unemployment even though expectations are rational, no nominal wage- or price-rigidity exists, and no privately attainable gains from trade are left unexploited. It also allows output and employment to fluctuate with only small movements in aggregate real wages, but without invoking an implausibly large elasticity of labor-supply or anti-cyclical quit rates. Indeed the household sector is specified in such a way that the usual measure of labor-supply elasticity is zero, and the aggregate quit-rate is assumed constant.

Another purpose of the model is to argue by example that one cannot infer from the ability or inability of new classical business cycle models to account for cyclical comovements in aggregate output and price time-series anything about the welfare propositions often associated with such models. In 
particular, a linear approximation to the present model yields a relationship between output and price-surprises identical to the Lucas (1973) aggregatesupply relationship except for a time delay. Such a relationship is derived by Sargent (1979, Ch. 16) from a model in which observed equilibria are Pareto-optimal. But in the present model equilibria are generally not optimal, because of externalities in the labor market.

A third purpose of the model is to show how this approach to labor markets can yield implications concerning the aggregate effects of relativeprice shocks. The externalities in the labor market imply a non-linearity in the response of employment in each sector to perceived changes in relative-output prices. It is shown that because of this non-linearity an increase in either the variability or persistence of relative-price shocks causes both an increase in the natural rate of unemployment and an increase in the initial impact upon employment of a monetary shock.

In order to focus upon the effects of costs of trading in labor markets the paper makes a number of simplifying assumptions that severely limit the ability of agents to communicate offers to buy and sell labor. For the same reason, and to facilitate comparison with new classical models, the specification of output markets follows closely the elementary treatment of Lucas (1973). As a result the model is too simple from an economic point of view to take seriously as anything but an example of the kind of results that can follow from this alternative conception of labor markets. In particular, the fact that it embodies (to a linear approximation) a Lucas aggregate-supply relationship leaves it open to the criticism that the price-surprise mechanism at the heart of that relationship is probably too weak to account for the observed cyclical variability of output. It is my belief, however, that many of the insights of the present paper can be incorporated into richer 
models with more complex patterns of labor-market interaction and with alternative mechanisms and features such as nominal contracts, intertemporal substitution, or productivity shocks to account for output fluctuations.

The paper is organized as follows. Section 1 outlines the basic assumptions of the model, focussing upon the logistics of trading in the labor market. Section 2 discusses the determination of output prices. Section 3 discusses wage-determination. Section 4 analyzes the search and recruiting decisions faced by households and firms. Section 5 describes the working of the complete model. Section 6 discusses the relationship of the present model to others and points out how it avoids the particular shortcomings attributed above to Keynesian and classical macroeconomics. Section 7 analyzes the optimality properties of the model. Section 8 shows the effects of the variance and persistence of relative-price shocks and how Lilien's results might thereby be explained.

\section{Basics}

There are $J$ sectors in the economy, each with $F$ identical firms and $L$ identical workers. Firms remain always in the same sector. Each worker is temporarily attached to one sector, but is constantly subject to exogenous relocation (no voluntary mobility is permitted). The probability that a worker will be relocated during the current period is a constant, $\delta \in(0,1)$; thus the duration $\Delta$ of his attachment to his current sector is distributed according to the geometric density function $\delta(1-\delta)^{\Delta} ; \Delta=0,1, \ldots$. Once relocated a worker is assigned randomly to a new sector in such a way that an equal number of workers remains in each sector. ${ }^{1}$

Trading in the labor market of each sector is organized around a set of "contact points" distributed through space. Firms who wish to hire leave offers at these points, and workers wishing an offer must sample the points to find 
one. To emphasize the difficulty of finding a job assume that the only situation in which it is technically feasible for a worker and firm to communicate is that in which the worker has sampled a contact point at which the firm has left an offer that period. Once such a "contact" has been made the two parties can bargain over a contingent real wage contract. It is possible for the worker to remain working for the firm it has contacted, with no additional contacting activities required by either side, until he is relocated. Indeed in the equilibrium described below all contacts will result in such a contract that lasts until relocation.

Output of each sector is sold in a market that clears in the usual Walrasian sense. Each period the quantity supplied is determined by the amount of employment, which has already been determined by previous contacting activities. - Demand is determined by an exogenous stochastic process to be described below. As buyers of output each agent must be presumed to observe all output prices. But as buyer or seller of labor each agent is assumed to observe only the nominal price of his own sector's output. This gives rise to the familiar Phelps-Lucas signal extraction problem that permits unanticipated monetary disturbances to have real effects.

Since our focus is on the labor market, demand functions for outputs and money will be postulated directly rather than being derived from underlying maximization problems. Still, in order to analyze labor-market decisions it helps to specify indirect worker-utility functions with real wages and other labor-market variables as arguments. Let $w_{t}$ denote the real wage available to a worker at date $t\left(w_{t}=0\right.$ if he has no contract). Then his utility function at date $t$ is:

$$
\sum_{i=0}^{\infty} \beta^{i}\left(\left(w_{t+i}-\underline{w}\right) l_{t+i}-\sigma \cdot s_{t+i}\right)
$$

where the discount factor is $\beta \in(0,1)$, the cost of giving up full-time leisure is $\underline{w}>0$, the cost of search is $\sigma>0, \ell_{t}$ is a dichotomous work variable 
equal to one if he $1 s$ working at dace $c$ and zero otherwise, and $s_{t}$ is an analogously dichotomous search variable. The parameters $\beta$, $\underline{w}$, and $\sigma$ are the same for all workers. According to this function workers are risk-neutral when choosing between wage profiles. Also, the cost of search is independent of whether or not the worker is currently working.

All firms produce according to a linear homogeneous production function with labor as the only input. Let $y_{t}^{j}$ and $n_{t}^{j}$ denote output and employment of each firm in sector $j$, date $t$. Then $y_{t}^{j}=f n_{t}^{j}, f>0$.

Let $w_{t}^{j}$ and $\pi_{t}^{j}$ denote the real wage paid and relative output-price received by each firm in sector $j$, date $t$. Then the objective function of such a firm is:

$$
\sum_{i=0}^{\infty} \beta^{i}\left(\left(\pi_{t+i}^{j} f-w_{t+i}^{j}\right) n_{t+i}^{j}-c_{t+i}^{j}\right)
$$

where $c_{t+i}^{j}$ is the firm's cost of recruiting. The firm's recruiting technology will be specified in Section 4 below. According to this objective function firms are also risk-neutral and use the same rate of time discount as workers.

2. Output Prices and Expectations

Aggregate employment and output are $n_{t} \equiv \sum_{j=1}^{J} n_{t}^{j}$ and $y_{t} \equiv f n_{t}$ respectively. Let $p_{t}^{j}$ denote the nominal price of output in sector $j$. The aggregate price-level is $p_{t} \equiv \sum_{j=1}^{J} p_{t}^{j} y_{t}^{j} / y_{t}$. The relative price of output in sector $j$ is defined as $\pi_{t}^{j} \equiv p_{t}^{j} / p_{t}$

Following Lucas (1973) assume that the relative prices $\pi_{t}^{j}$ are determined by an exogenous stochastic process representing the effects of random shifts in tastes. Specifically: 
(1)

$$
\left\{\begin{array}{l}
\left(\pi_{t}^{j}-1\right)=\rho\left(\pi_{t-1}^{j}-1\right)+v_{t}^{j}=\sum_{i=0}^{\infty} \rho^{i} v_{t-i}^{j}, 0<\rho<1, \sum_{j=1}^{j} v_{t}^{j}=0 \text { in all } \\
\text { realizations, } v_{t}^{j} \text { distributed identically for each } j, t, \\
\text { independent1y of each } v_{t^{\prime}}^{j^{\prime}} \text { for which } t^{\prime} \neq t, \text { with } E\left(v_{t}^{j}\right)^{2}=\sigma_{v}^{2} \text {; and } \\
v_{t}^{j} \in(-\underline{v}, \bar{v}) \forall j, t \text { where } 0<\underline{v}<(1-\rho) .
\end{array}\right.
$$

Note that, according to (1) $\mathrm{Ev}_{t}^{j}=0$, and if $\pi_{t-1}^{j}>0$ then $\pi_{t}^{j}>0$.

Let $M_{t}$ denote the nominal stock of money and $\nu_{t}$ its income-velocity.

Again following Lucas assume that nominal aggregate demand follows a stochastic difference equation:

$$
\left\{\begin{array}{l}
\nu_{t}{ }_{t}=g_{t}\left(\nu_{t-1}{ }_{t-1}, \ldots, \nu_{t-q} q_{t-q}\right)\left(1+m_{t}\right),\left\{m_{t}\right\} \text { white noise distributed } \\
\text { independently of }\left\{v_{t}^{j}\right\} \forall j, \text { with mean zero, variance } \sigma_{m}^{2} \text { and } 1+m_{t}>0 \\
\text { in a11 realizations, } g_{t}(\cdot)>0 \text { on } \Omega^{q} .
\end{array}\right.
$$

The price-level must satisfy the equilibrium condition:

$$
p_{t} y_{t}=\nu_{t} M_{t}=g_{t}\left(\nu_{t-1} M_{t-1}, \ldots, v_{t-q} M_{t-q}\right)\left(1+m_{t}\right)
$$

The information set $I_{t}$ common to agents in all sectors at the end of period $t$ consists of the relative prices $\left(\pi_{t}^{1}, \ldots, \pi_{t}^{J}\right)$, the employment levels $\left(n_{t}^{2}, \ldots, n_{t}^{J}\right)$ and the previous values $\left\{\nu_{T} M_{T}\right\}_{T=t-q+1}^{T=t}$ of nominal aggregate demand. The information set $I_{t}^{j}$ of all agents in sector $j$ at the time of recruiting decisions and wage negotiations consists of $I_{t-1}$ and the current realization $p_{t}^{j}$ of the nominal price of that sector's output. Denote by $E_{t}$ and $E_{t}^{j}$ the expectations operators conditional on $I_{t}$ and $I_{t}^{j}$ respectively.

The expectation of $p_{t}$ formed at the end of period $t-1$ can be derived by taking the conditional expectation of (3), using (2) and the definition of $y_{t}$ :

$$
\left(E_{t-1} P_{t}\right) y_{t}=E_{t-1} \nu_{t} M_{t}=g_{t}\left(\nu_{t-1} M_{t-1}, \ldots, \nu_{t-q} M_{t-q}\right)
$$


From (3) and (4), the shock to aggregate demand is also the price-surprise term of Lucas's aggregate supply schedule:

$$
\left(\frac{P_{t}}{E_{t-1} P_{t}}\right)-1=m_{t}
$$

It also follows directly from (1) that the relative-price surprise is the relative-price shock:

$$
\pi_{t}^{j}-E_{t-1} \pi_{t}^{j}=v_{t}^{j}
$$

The signal extraction problem facing agents in sector $j$ is to infer the value of the current relative-price shock $v_{t}^{j}$ from knowledge of $I_{t}^{j}$. It helps in modeling the solution to that problem to make two approximations. The first is to approximate the information set $I_{t}^{j}$ by the set consisting of $I_{t-1}$ and the sum $v_{t}^{j}+m_{t}$ of the relative-price and aggregate-demand shocks. The justification for this approximation is that a first-order Taylor's series approximation around the point: $p_{t}=E_{t-1} p_{t}, \pi_{t}^{j}=1$ yields :

$$
\begin{aligned}
& p_{t}^{j} \\
\equiv & \pi_{t}^{j} p_{t} \\
\Rightarrow & E_{t-1} p_{t}+\left(\pi_{t}^{j}-1\right) E_{t-1} p_{t}+\left(p_{t}-E_{t-1} p_{t}\right) \\
= & E_{t-1} p_{t}\left[E_{t-1} \pi_{t}^{j}+\left(\pi_{t}^{j}-E_{t-1} \pi_{t}^{j}\right)+\left(\frac{p_{t}}{E_{t-1} p_{t}}-1\right)\right] \\
= & E_{t-1} P_{t}\left[E_{t-1} \pi_{t}^{j}+v_{t}^{j}+m_{t}\right] .
\end{aligned}
$$

(The last line follows from (5) and (6).) Thus observing $I_{t}^{j}$ is approximately the same as observing $I_{t-1}$ together with the last expression above, which is equivalent to observing $\left\{I_{t-1}, v_{t}^{j}+m_{t}\right\}$.

The second approximation is to treat conditional expectations as identical to least-squares projections. This would not require an approximation if $v_{t}^{j}$ 
and $m_{t}$ were normal, but the restrictions in (1) and (2) which bound the supports of these randon variables are inconsistent with normality.

Using those two approximations we can use Sargent's rules for recursive projections (1979, Pp. 206-7) to derive the conditional expectation of the relative price shock:

$$
E_{t}^{j} v_{t}^{j}=E\left(v_{t}^{j} \mid v_{t}^{j}+m_{t}\right)=\eta\left(v_{t}^{j}+m_{t}\right)
$$

where $\eta \equiv \frac{\sigma_{v}^{2}}{\sigma_{v}^{2}+\sigma_{m}^{2}}$.

\section{Wage Determination}

Assume that once a labor-market contact has been made the worker cannot make another contact that period. The firm and worker will thus bargain in a situation of bilateral monopoly. The firm will benefit from any contract that gives it a positive expected present value, and the worker.will benefit from any contract with some chance of a real wage greater than $\underline{w}$ in any period. This leaves a zone of indeterminacy. In the interest of simplicity assume that this indeterminacy is resolved by an outcome that splits the gains from trade in a predetermined fixed proportion。

Formally, the gain accruing to the firm in period $t$ (provided the worker has not been relocated or quit) is $\pi_{t}^{j} f-w_{t}^{j}$, whereas the corresponding gain to the worker is $w_{t}^{j}-w$. Let $\xi \in(0,1)$ be the fraction of the total gain accruing to the worker. Then the wage contract will specify:

$$
w_{t}^{j}=\underline{w}+\xi\left(\pi_{t}^{j} f-\underline{w}\right)
$$

Assume that the range of variation of $v_{t}^{j}$ is restricted sufficiently that for some number $x_{1}>0$,

$$
\pi_{t}^{j} f-\underline{w} \geqq n_{1} \quad \text { in all realizations. }
$$


It follows from (8) and (9) that both parties receive a strictly positive gain:

$$
\pi_{t}^{j} f-w_{t}^{j} \geqq x_{1}(1-\xi)>0 \text { and } w_{t}^{j}-\underline{w} \geqq n_{1} \xi>0 \text { in all realizations. }
$$

The wage contract (8) is efficient in the sense that if both parties take as given the decisions of all other agents, as well as the outcomes of all future bargains, and if all other negotiations result in the same contract, then there is no alternative contract that two parties could agree upon that would make them each better off. Intuitively this is because as long as the worker works each period until exogenous relocation there is no way of increasing the total gain to the two parties in any period. Search can only allow the worker to attain the same prospect elsewhere at a cost to him and to his present employer. Variations in the contracted wage merely affect the share of total gain going to each party, without affecting the total. The importance of this efficiency result merits a somewhat more formal demonstration in spite of its intuitive obviousness. The rest of this section is devoted to such a demonstration.

First, some behavioral assumptions must be made explicit. Assume that firms can precommit but workers cannot. Thus once a contract is agreed to the firm will continue to offer employment at the agreed-upon wage as long as the worker chooses to work and is available. The worker will not work, however, whenever it is in his short-run interest not to do so (whenever $w_{t}^{j}<\underline{w}$ ), and will search for another offer of the form (8) within the same sector whenever it is profitable to do so. If he accepts another offer he cannot return to his present employer except by recommencing the search process as if contact had never been made. If he merely chooses not to work and is not relocated he can costlessly take up re-employment at the agreed upon wage at any future date. 
Let $w_{t}^{j}$ denote the worker's expected present value of accepting the wage contract (8) in sector $j$, as of date $t$. Let $v_{t}^{(j)}$ denote the expected present value of being relocated from sector $j$. A worker who agrees to the contract (8) will never search when all other firms are offering (8) because the cost of search is positive. Likewise, (10) implies that such a worker will always choose to work until relocated. Once a contract has been signed it takes one period to put the worker on line, in which period he remains subject to relocation. The probability that relocation will not have occurred $i$ periods after contact is $(1-\delta)^{i}$. the probability of relocation then is $(1-\delta)^{i-1} \delta$. Therefore:

$$
W_{t}^{j}=E_{t}^{j} \sum_{i=1}^{\infty} \beta^{i}(1-\delta)^{i-1}\left((1-\delta)\left(w_{t+i}^{j}-w\right)+\delta V_{t+i}^{(j)}\right)
$$

Assume that the cost to the firm of all past and present recruiting activities, including those involving the worker with whom the bargain is now taking place, are sunk at the time of the bargain. Assume also that future recruiting costs are unaffected by the outcome of the present bargain. The latter assumption appears to be consistent with the firm's assumed inability to communicate with workers except through the contacting process. In particular it is unable unilaterally to induce more workers to search, to induce more rapid search, to bias the searchers' selection of contact points, or in any other way to motivate searchers to assume more of the costs of future contacting, merely by demonstrating its willingness to agree to generous wage contracts.

Under these assumptions the expected present value to the firm of signing the contract ( 8 ) at date $t$ is:

$$
\lambda_{t}^{j}=E_{t}^{j} \sum_{i=1}^{\infty} \beta^{i}(1-\delta)^{i}\left(\pi_{t+i}^{j} f-w_{t+i}^{j}\right)
$$

Thus the sum of present values to the two parties to a contract of form (8) is:

$$
\mathscr{J}_{t}^{j} \equiv w_{t}^{j}+\lambda_{t}^{j}=E_{t}^{j} \sum_{i=1}^{\infty} \beta^{i}(1-\delta)^{i-1}\left((1-\delta)\left(\pi_{t+i}^{j} f-\underline{w}\right)+\delta V_{t+i}^{(j)}\right)
$$


Consider any alternative contract of the form $\tilde{w}_{t}^{j}$ (possibly random). Let $T$ be the (random) number of periods beyond contact at which a worker who followed the optimal search strategy under this alternative contract, and who was lucky enough never to be exogenously relocated, would quit to accept an offer, and let $s_{t}$ describe that optimal strategy. Then the value to the worker of accepting this alternative contract is:

$$
\tilde{W}_{t}^{j}=E_{t}^{j}\left\{\sum_{i=1}^{T} \beta^{i}(1-\delta)^{i-1}\left((1-\delta)\left(\left(\tilde{w}_{t+i}^{j}-\underline{w}\right) l_{t+i}-\sigma s_{t+i}\right)+\delta V_{t+i}^{(j)}\right)+\beta^{T}(1-\delta)^{T} W_{t+T}^{j}\right\}
$$

where $\ell_{t+i}$ equals 1 if $\tilde{w}_{t+i}^{j} \geqq \underline{w}$ and 0 otherwise. The value to the firm from this alternative contract is:

$$
\tilde{\lambda}_{t}^{j}=E_{t}^{j} \sum_{i=1}^{T} \beta^{i}(1-\delta)^{i}\left(\pi_{t+i}^{j} f-\tilde{w}_{t+i}^{j}\right) \ell_{t+i}
$$

The sum of values from the alternative contract is thus:

$$
\begin{aligned}
\tilde{\partial}_{t}^{j} \equiv \tilde{w}_{t}^{j}+\tilde{\lambda}_{t}^{j}=E_{t}^{j} & \sum_{i=1}^{T} \beta^{i}(1-\delta)^{i-1}\left((1-\delta)\left(\left(\pi_{t+i}^{j} f-\underline{w}\right) \ell_{t+i}-\sigma s_{t+i}\right)\right. \\
& \left.\left.+\delta V_{t+i}^{(j)}\right)+\beta^{T}(1-\delta)^{T} w_{t+T}^{j}\right\}
\end{aligned}
$$

To demonstrate our efficiency claim we need only show that $\tilde{z}_{t}^{j}-\tilde{\partial}_{t}^{j} \geqq 0$. To do this, note that:

$$
\begin{aligned}
\tilde{\partial}_{t}^{j}-\tilde{\partial}_{t}^{j}=E_{t}^{j}\left\{\sum_{i=1}^{T} \beta^{i}(1-\delta)^{i}\left(\left(\pi_{t+i}^{j} f-\underline{w}\right)\left(1-l_{t+i}\right)+\sigma s_{t+i}\right)\right. \\
\left.+\sum_{i=T+1}^{\infty} \beta^{i}(1-\delta)^{i-1}\left((1-\delta)\left(\pi_{t+i}^{j} f-\underline{w}\right)+\delta V_{t+i}^{(j)}\right)-\beta^{T}(1-\delta)^{T} W_{t+T}^{j}\right\}
\end{aligned}
$$

It follows from (9) and the facts that $\ell_{t+i} \leqq 1, \sigma>0$, and $s_{t+i} \geqq 0$ that the first sum in the above expression is non-negative. Therefore the common factor can be extracted from the second sum to derive the result:

$$
\tilde{\partial}_{t}^{j}-\tilde{\partial}_{t}^{j} \geqq E_{t}^{j} \beta^{T}(1-\delta)^{T}\left\{\sum_{i=1}^{\infty} \beta^{i}(1-\delta)^{i-1}\left((1-\delta)\left(\pi_{t+T+i}^{j} f-\underline{W}\right)+\delta V_{t+T+i}^{(j)}\right)-w_{t+T}^{j}\right\}
$$

Substituting from (11) into this last expression yields 


$$
\tilde{z}_{t}^{j}-\tilde{y}_{t}^{j} \geqq E_{t}^{j} \beta^{T}(1-\delta)^{T} \sum_{i=1}^{\infty} \beta^{i}(1-\delta)^{i}\left(\pi_{t+T+i}^{j} f-w_{t+T+i}^{j}\right)
$$

From (10) the R.H.S. of this inequality is non-negative, which establishes our result. (Note that although the inequality in (10) is strict, it is possible that $\tilde{g}_{t}^{j}-\tilde{J}_{t}^{j}=0$ because the probability that $T$ is finite could be zero.)

The efficiency of the contract (8) does not imply social efficiency. It merely shows that no group of bargainers can make. themselves better off given the outcomes of all. other present and future bargains. In this sense workers and firms are exploiting all privately attainable gains from trade. The question of social efficiency will be addressed in Section 7 below.

\section{Search and Recruiting}

When searching, a worker can sample only one contact point per period. Let $\theta_{t}^{j}$ denote the fraction of all contact points at which each firm in sector $j$ leaves an offer at date $t$. Suppose that there is no possibility of more than one offer being left at one point. Then the probability that a searching worker will receive an offer is $F \theta_{t}^{j}$. In the equilibrium described in the next section $\theta_{t}^{j}$ will be a function of the random elements of $\mathrm{I}_{t}^{j}$. Assume that for some positive numbers $x_{2}$ and $x_{3}:$

$$
1-x_{3} \geqq F \theta_{t}^{j} \geqq x_{2} \text { for all realizations, all } j, t \text {. }
$$

By definition, the number of unemployed workers is:

$$
u_{t}^{j}=L-F n_{t}^{j}
$$

By the discussion of the previous section none of the unemployed has a contract. Thus, the only decision for the unemployed is whether or not to search. Assume that 
the cost of search is small enough to satisfy the inequality:

$$
\sigma<x_{1} x_{2} \xi \beta(1-\delta)
$$

Then it will be optimal for all unemployed workers to search in every state of the world. To see this, let $v_{t}^{j}$ denote the expected utility of an unemployed worker. If he chooses not to search he will have an expected utility of:

$$
E_{t}^{j} j_{\beta}\left((1-\delta) V_{t+1}^{j}+\delta V_{t+1}^{(j)}\right)
$$

If he chooses to search he will have:

$$
\left.-\sigma+F \theta_{t}^{j} W_{t}^{j}+\left(1-F \theta_{t}^{j}\right) E_{t}^{j} \beta(1-\delta) v_{t+1}^{j}+\delta v_{t+1}^{(j)}\right)
$$

The net gain from searching is therefore:

$$
A_{t}^{j}=-\sigma+F \theta_{t}^{j} E_{t}^{j}\left(w_{t}^{j}-\beta\left((1-\delta) V_{t+1}^{j}+\delta V_{t+1}^{(j)}\right)\right)
$$

and an unemployed worker will search whenever $\Delta_{t}^{j}>0$. From (11) and. (16):

$$
\begin{aligned}
A_{t}^{j}= & -\sigma+F \theta_{t}^{j} E_{t}^{j}\left(\beta\left((1-\delta)\left(w_{t+1}^{j}-\underline{w}\right)+\delta V_{t+1}^{(j)}\right)+\sum_{i=2}^{\infty} \beta^{i}(1-\delta)^{i}\left((1-\delta)\left(w_{t+i}^{j}-\underline{w}\right)+\delta V_{t+i}^{(j)}\right)\right. \\
& \left.-\beta(1-\delta) V_{t+1}^{j}-\beta \delta V_{t+1}^{(j)}\right) \\
= & -\sigma+\beta(1-\delta) F \theta_{t}^{j} E_{t}^{j}\left(w_{t+1}^{j}-\underline{w}+w_{t+1}^{j}-V_{t+1}^{j}\right)
\end{aligned}
$$

Since someone who has a contract could always choose to search for a contract, therefore $\mathrm{w}_{\mathrm{t}+1}^{\mathrm{j}} \geqq \mathrm{V}_{\mathrm{t}+1}^{\mathrm{j}}$, so that:

$$
\Delta_{t}^{j} \geqq-\sigma+\beta(1-\delta) F \theta_{t}^{j} E_{t}^{j}\left(w_{t+1}^{j}-\underline{w}\right)
$$

From this, together with (10) and (13): 


$$
4^{j} \geq-\sigma+\beta(1-\delta) x_{2} x_{1} \quad \text { in all realizations. }
$$

From this and (15):

$$
\hat{L}^{j}>0 \text { in all realizations. }
$$

Therefore all unemployed workers will always search.

To describe the firm's recruiting decision, assume that each firm knows with certainty that the fraction $\delta$ of its work force will be relocated every period, and that if it places offers at the fraction $\theta_{t}^{j}$ of all possible contact points then the number of workers it will hire, $h_{t}^{j}$, is that same fraction of the number unemployed:

$$
h_{t}^{j}=\theta_{t}^{j} v_{t}^{j}
$$

The firm's recruiting cost depends not only upon $h_{t}^{j}$ but also upon $U_{t}^{j}$, because to hire a given number of workers requires more offers to be made the fewer unemployed there are. (by (17)) and making offers is costly. Accordingly, the cost of recruiting is assumed to take the form: ${ }^{3}$

$$
c_{t}^{j}=(G / 2)\left(h_{t}^{j}\right)^{2} / U_{t}^{j}, G>0
$$

The marginal cost of recruiting is thus $\mathrm{Gh}_{t}^{j} / \mathrm{U}^{j}$. That this marginal cost is increasing in $h_{t}^{j}$ is required, as in other stock-adjustment factor-demand models (e.g., Treadway, 1969) in order to yield a well-behaved flow-demand. That it is decreasing in $U_{t}^{j}$ accords with our previous discussion.

The firm at date $t$ takes $U_{t}^{j}$ as given. It also takes as given that the workers it hires will bargain successfully for the contract (8), so that the expected marginal value of each worker hired will be $\lambda_{t}^{j}$, given by (12) above. Thus the firm will choose a rate of hiring that equates marginal cost and expected marginal value: 


$$
h_{t}^{j}=G^{-1} U_{t}^{j} \lambda_{t}^{j}
$$

According to (17) and (19) it will choose a recruiting intensity equal to:

$$
\theta_{t}^{j}=G^{-1} \lambda_{t}^{j}
$$

This description of labor markets implies externalities of the sort emphasized by Diamond (1982b). The welfare of an unemployed household depends directly upon the recruiting intensity $\theta_{t}^{j}$ chosen by firms. Likewise the expected profits of a firm are positively affected by the number unemployed, $\mathrm{U}_{t^{j}}^{j}$. These are both examples of an external economy that results when more contacting activity on one side of the market makes trading easier for those on the other side. This external benefit cannot be internalized because, by assumption, the contacting activities giving rise to the benefits must be conducted before any internalizing agreements can be negotiated.

This description also implies an external diseconomy of the sort found in common-property natural-resource models. One of the costs of hiring today is a reduction in the number unemployed in the future, which raises the cost of hiring in the future. This cost is not taken into account by the individual firm, which is assumed to take the time-path $U_{t}^{j}$ as exogenous with respect to its own hiring decisions. The importance of this external diseconomy will be discussed below in Section 7.

\section{Equilibrium}

The definition of $h_{t}^{j}$ and our assumptions concerning exogenous relocation imply that employment in each sector will evolve according to:

$$
n_{t+1}^{j}=(1-\delta)\left(n_{t}^{j}+h_{t}^{j}\right) .
$$

Therefore (19) and (21) can be written as: 
(22)

$$
n_{t+1}^{j}=(1-\delta) n_{t}^{j}+(1-\delta) G^{-1} v_{t}^{j} \lambda_{t}^{j}
$$

From (1), (7), (8) and (12), straightforward calculations yield:

$$
\lambda_{t}^{j}=\bar{\lambda}+\alpha\left(\rho\left(\pi_{t-1}^{j}-1\right)+\eta\left(v_{t}^{j}+m_{t}\right)\right)
$$

where

$$
\bar{\lambda} \equiv \beta(1-\delta)[1-\beta(1-\delta)]^{-1}(f-\underline{w})(1-\xi)>0
$$

(the inequality follows from (9)), and:

$$
\alpha \equiv \beta(1-\delta) \rho[1-\beta(1-\delta) \rho]^{-1} f(1-\xi)>0 .
$$

Note that $\bar{\lambda}$ is the expected value of $\lambda_{t}^{j}$.

For present purposes, the most Important feature of the expression (23) is the dependence of the value of hiring upon the monetary surprise, $\mathrm{m}_{t} \cdot$ This dependence arises because of the Lucas price-surprise mechanism derived in Section 2 whereby an increase in $m_{t}$ raises each firm's conditional expectation of its current relative-price shock, $E_{t}^{j} v_{t}^{j}$, with a coefficient $\eta_{0}$ In the present context the strength of the resulting effect on the value of hiring depends upon $\rho$, the degree of persistence of relative-price shocks. Because hiring is costly the decision to hire is based upon not only present but also expected future relative prices of the firm's output. The greater is $\rho$ the greater the effect upon these expected future relative prices of any change in $E_{t}^{j} v_{t}^{j}$, and hence the greater the effect upon the marginal value of hiring that results from a monetary surprise that induces such a change in $E_{t}^{j} v_{t}^{j}$.

To understand the dynamic behavior of the model it helps to begin by analyzing an isolated firm that takes as given the stochastic behavior of both 
$v_{t}^{j}$ and $\lambda_{t}^{j}$. That firm's employment will vary according to the stochastic difference equation (22).

Note that the firm's employment will be positively affected by a monetary shock. Specifically, an increase in $\mathrm{m}_{t}$ will increase $\lambda_{t}^{j}$ (by (23)) through the Lucas price-surprise mechanism, which will increase the hiring rate $h_{t}^{j}=G^{-1} U_{t}^{j} \lambda_{t}^{j}$ and thereby increase next period's employment.

Note also that the size of this effect of a monetary shock is greater the greater is unemployment in the firm's sector. This non-linearity is the source of the effects to be analyzed below in Section 8. It arises because of the externality described in the previous section according to which the marginal cost of hiring depends upon the number unemployed. Intuitively speaking, a firm in a tight labor market will be relatively unresponsive to a perceived increase in the marginal value of hiring because of the difficulty of finding recruits.

Next, note that this stochastic difference equation is stable because $\frac{\partial n_{t+1}^{j}}{\partial n_{t}^{j}}=(1-\delta) \in(0,1)$. The economic interpretation of this effect is straightforward. For each additional worker this period, (1- $\delta$ ) workers will remain after relocation, and according to (19) the increase in the isolated firm's employment this period will not affect his hiring; thus next period's employment will increase by the full amount (1- $\delta)$. Fina11y, note that, because $\frac{\partial n_{t+1}^{j}}{\partial n_{t}^{j}}>0$, the positive effect of a monetary shock will persist into future periods, being embodied each period in a higher value of last period's employment, despite the fact that the future values of $\lambda_{t}^{j}$ will be unaffected by the shock. 
To pass from the dynamics of the isolated firm to the equilibrium dynamics of the model substitute for $\mathrm{U}_{t}^{j}$ in (21) using (14). This results in the non-linear stochastic difference equation:

$$
n_{t+1}^{j}=(1-\delta)\left(n_{t}^{j}+G^{-1}\left(L-F n_{t}^{j}\right) \lambda_{t}^{j}\right)
$$

According to (26) the impact effect of a monetary shock upon the equilibrium value of next period's employment is exactly as described above for the isolated firm. Employment rises by the amount of the increase in $\lambda_{t}^{j}$ multiplied by the predetermined value of $(1-\delta) G^{-1} U_{t}^{j}=(1-\delta) G^{-1}\left(L-F n_{t}^{j}\right), 1, e_{.}$, by $(1-\delta)$ times the increase in the firm's desired rate of hiring. Thus the increase in employment comes about not because workers are fooled or in any way induced to offer more labor for sale, but because the increase in hiring allows them to find jobs more rapidly. The supply side of the labor market affects this impact effect only in the sense that, as described above, the effect will be greater the more unemployed workers there are.

Next note that, according to (13), (20) and (26): $\frac{\partial n_{t+1}^{j}}{\partial n_{t}^{j}}=(1-\delta)\left(1-G^{-1} F \lambda_{t}^{j}\right) \epsilon$ $(0,1)$. This means, as before, that the deterministic counterpart to the difference equation is stable, and that the effect of a monetary shock will persist. To interpret this effect note that if an increase in this period's employment is shared by all firms then it will be accompanied by a decrease in the number unemployed this period, and, through the externality described in the previous section, will cause each firm to reduce its hiring by an amount equal to the change in unemployment times $G^{-1} \lambda_{t}^{j}$. Therefore, the change in each firm's employment next period will be less than it would have been if the firm had been the only one to experience the increase. Assumption (13) limits the extent of the reduction in hiring and guarantees that the overall effect upon next period's employment is still positive. 
Next we show that according to (26) if there is ever any unemployment there will always be unemployment; specifically, we show that:

$$
\text { For any } t \text {, if } n_{t}^{j} \in(0, L / F) \text { then } n_{t+1}^{j} \in(0, L / F) \text {. }
$$

To show this first note that, from (13) and (20):

$$
F G^{-1} \lambda_{t}^{j} \in(0,1)
$$

From (28), $n_{t+1}^{j}=(1-\delta)\left(G^{-1} L \lambda_{t}^{j}+\left(1-F G^{-1} \lambda_{t}^{j}\right) n_{t}^{j}\right) \mathcal{E}\left(0,(1-\delta)\left(G^{-1} L \lambda_{t}^{j}+\left(1-F G^{-1} \lambda_{t}^{j}\right)(L / F)\right)\right)$

$=(0,(1-\delta)(\mathrm{L} / \mathrm{F})) \subset(0, \mathrm{~L} / \mathrm{F})$.

To demonstrate the existence of an ergodic stationary solution to (26)

it helps to transform it. First, define:

$$
\bar{n} \equiv \frac{(1-\delta) G^{-1} \bar{L} \bar{\lambda}}{\delta+(1-\delta) G^{-1} \bar{F} \bar{\lambda}} \in(0, L / F) \text {, and }
$$

$$
a \equiv(1-\delta)\left(1-G^{-1} \bar{F} \bar{\lambda}\right)
$$

Because $\bar{\lambda}$ is the expected value of $\lambda_{t}^{j}$ it follows from (28) that:

$$
a \in(0,1)
$$

Next, define

$$
\varepsilon_{t}^{j} \equiv \gamma\left(\sum_{i=1}^{\infty} \rho^{i} v_{t-i}^{j}+\eta\left(v_{t}^{j}+m_{t}\right)\right)
$$

where

$$
\gamma \equiv(1-\delta) G^{-1}(L-F \bar{n}) \alpha,
$$

and.

(34)

$$
x_{t}^{j} \equiv n_{t}^{j}-\bar{n}
$$

Then a series of straightforward calculations shows that (26) can be rewritten as : 


$$
x_{t+1}^{j}=a x_{t}^{j}-b x_{t}^{j} \varepsilon_{t}^{j}+\varepsilon_{t}^{j}
$$

where, by (29):

$$
\mathrm{b} \equiv \frac{\mathrm{F}}{\mathrm{L}-\mathrm{F} \overline{\mathrm{n}}}>0
$$

Except for the fact that $\varepsilon_{t}^{j}$ is not white noise (35) is a bilinear timeseries model of the sort studied by Granger and Anderson (1978). A slightly modified version of the theorem of Quinn (1982) states that if for some subsets $x_{1}$ and $x_{2}$ of the real numbers,

$$
e_{t}^{j} \text { has a strictly stationary ergodic distribution on } x_{2}
$$

$$
a x_{t}^{j}-b x_{t}^{j} \varepsilon_{t}^{j}+\epsilon_{t}^{j} \in x_{1} \quad \text { for all }\left(x_{t}^{j}, \varepsilon_{t}^{j}\right) \in x_{1} X x_{2}
$$

$$
E \ln \left|a-b \varepsilon_{t}^{j}\right|<0 \text {, and }
$$

$$
E|\ln | x+\varepsilon_{t}^{j}||<\infty \text { for all } x \in X_{1}
$$

then (35) has a strictly stationary, ergodic solution on $\mathrm{X}_{1}$, which can be written, using (34), as :

$$
n_{t}^{j}=\bar{n}+\varepsilon_{t-1}^{j}+\sum_{k=2}^{\infty} \prod_{\ell=1}^{k-1}\left(a-b \varepsilon_{t-l}^{j}\right) \varepsilon_{t-k}^{j} .
$$

Let $x_{1}$ be the interval $(-\bar{n},(L / F)-\bar{n})$, and $x_{2}$ be the interval $\left(-\gamma \bar{\lambda} / \alpha, \gamma\left(G F^{-1}-\bar{\lambda}\right) / \alpha\right)$. Assume that (40) holds. We now show that (37) (39) also hold, and hence that a solution of the form (41) exists.

From (23) and (32),

$$
\epsilon_{t}^{j} \equiv(\gamma / \alpha)\left(\lambda_{t}^{j}-\bar{\lambda}\right)
$$

Therefore, by (28), (29) and (33), $\varepsilon_{t}^{j} \in X_{2}$ in all realizations. That $\varepsilon_{t}^{j}$ is strictly stationary and ergodic on $x_{2}$ follows from (1), (2) and (32). 
Therefore (37) holds. Condition (38) follows directly from (27) and (34). From (28), (30), (33), (36) and (42): $a-b \varepsilon_{t}^{j} \equiv(1-\delta)\left(1-G^{-1} \bar{F} \bar{\lambda}\right)-\frac{F}{L-F \bar{n}}(1-\delta) G^{-1}(L-F \bar{n})\left(\lambda_{t}^{j}-\bar{\lambda}\right)$ $=(1-\delta)\left(1-G^{-1} F \lambda_{t}^{j}\right) \in(0,1)$ in all realizations. Condition (39) follows immediately. By substituting from the definition (32) of $e_{t}^{j}$ into the solutions (41) we can express employment in each sector as a function of past shocks:

(43)

$$
n_{t}^{j}=\hat{n}\left(\left\{m_{T}, v_{T}^{j}\right\}_{-\infty}^{t-1}\right)
$$

The function (43) constitutes the equilibrium of our model. 


\section{Comparison With Other Theories}

As the preceding discussion suggests, the relationship of this model to that of Lucas (1973), from which it borrows its price-surprise mechanism, is very close. Indeed the predictions of the two models concerning the interrelationships between price-surprises and aggregate output are almost identical. Specifically, a linear approximation to (26) around the point $(\bar{n}, \bar{\lambda})$ yields, after suming across sectors:

$$
n_{t+1} \sim n^{*}+a\left(n_{t}-n^{*}\right)+b^{\prime} \eta m_{t}
$$

where $n^{*} \equiv J_{\bar{n}}^{-}$and $b^{\prime} \equiv \alpha \delta n^{*} / \bar{\lambda}>0$. Changing variables and using (5) transforms this into:

$$
y_{t+1} \simeq y^{*}+a\left(y_{t}-y^{*}\right)+b^{\prime \prime} \cdot \eta\left(\frac{p_{t}}{E_{t-1} P_{t}}-1\right)
$$

where $y^{*} \equiv f n^{*}$ and $b^{\prime \prime} \equiv \mathrm{fb}^{\prime}$. This is the Lucas aggregate-supply relationship between aggregate output and price-surprises, except that, because it takes one period for newly hired workers to be put to work, the price-surprise in period $t$ becomes the innovation in $y_{t+1}$ rather than $y_{t^{*}}$

The present model derives this aggregate supply relationship from an approach which is similar to that followed by Sargent (1979, Ch, 16). . In both cases the persistence term $a\left(y_{t}-y^{*}\right)$, which Lucas did not derive explicitly, is derived from costs of changing employment. Indeed as far as the demand for labor is concerned the present model's treatment is almost a special case of Sargent's. What distinguishes the two approaches is the manner in which changes in the demand for labor induce changes in the equilibrium quantity of employment. As discussed above these changes do not 
represent movements up and down any supply-of-labor schedule in the present approach as they do in Sargent's.

This model also bears a close resemblance to the simple hypothesis put forth by Barro (1977) to account for unemployment. Another change of variables from the linear approximation to (26) together with a Koyck transformation yields an alternative form of Barro's unemployment equation:

$$
u_{t} \approx u^{*}+b^{\prime \prime \prime} \eta \sum_{i=0}^{\infty} a^{i} m_{t-i-1}
$$

where the rate of unemployment is $u_{t}=1-F n_{t} / J L$, the natural rate of unemployment is $\mathrm{u}^{*} \equiv 1-\mathrm{F} \mathrm{n}^{*} / \mathrm{JL}$, and $\mathrm{b}^{\prime \prime \prime} \equiv \mathrm{Fb} \mathrm{b}^{\prime} / \mathrm{JL}>0$. This model, like Barro's, predicts that, to a linear approximation, deviations of unemployment from its natural rate will be a distributed lag function of monetary shocks.

Even without any linear approximations the model yields the policyinvariance prediction usually associated with new classical models. The equilibrium (43) expresses employment in each sector as a function of monetary surprises and relative-price shocks, but these functions do not depend upon the functions $\mathrm{g}_{\mathrm{t}}$ describing the systematic component of nominal aggregate demand. Any predictable changes in nominal demand therefore have no real effects.

An interesting aspect of the model is that, because of the assumed lag involved in putting a newly hired worker to work, (26) implies that this period's employment in any sector will depend upon last period's monetary shock, even given employment in past periods. Thus the model implies that money will "cause" employment, in the Granger sense. Likewise the Iinear approximation to (26) yields the same "causality" prediction with respect 
to aggregate employment or output. Without such a lag the usual Lucas aggregate-supply relationship does not yield this policy prediction. Whether Sargent's derivation could easily be modified to incorporate a similar time-delay or whether it is a fundamental distinguishing feature of the present approach is not clear.

Although the present model bears these resemblances to new classical models it avoids the specific shortcomings attributed in the introduction to such models. First, it permits output in each sector to vary in the same direction in response to monetary shocks without large fluctuations in aggregate real wages (according to (1) and (8) the average wage across all sectors is the constant $\xi f+(1-\xi) \underline{w})$, but also without assuming an unrealistically large elasticity of labor-supply. Indeed we have specified household preferences in such a way that if each labor market were always in a competitive equilibrium the supply and demand for labor would always be equal at a real wage where the supply schedule was completely inelastic. (The real wage would equal the marginal product $\pi_{t}^{j} f$ and by (9) this would always exceed the disutility of full-time employment for all $\mathrm{L}$ workers in the sector.)

Second, the model does not imply anticyclical quit rates. (Quit rates are equal to the constant $\delta$ in all firms.)

Third, the model exhibits unemployment which is involuntary in the everyday sense of the word. Unemployed workers would always prefer to be employed. They are doing everything in their power to become employed, namely sampling one contact point per period. But they remain unemployed because it takes time to find a job. 4

The story we have told also avoids the specific shortcomings attributed above to the Keynesian approach to macroeconomics. No contractual rigidity 
of nominal prices is invoked. As we discussed earlier all contracts are privately efficient, so that no privately attainable gains from trade are being left unexploited. The impediments which prevent unemployed workers from underbidding employed workers are made explicit as part of the technology of exchange in the model. One might object that the impediments which limit people's abilities to communicate in the labor market are "ad hoc" in the sense that they are specified exogenously rather than being explained on the basis of even more primitive notions, but to eliminate this kind of "ad hocery" would require either the assumed absence of all impediments or an infinite regress to eliminate any exogenous notions giving rise to impediments.

\section{Social Efficiency}

Whether or not there are socially attainable gains from trade left unexploited is not easy to assess, since there are no explicit policy parameters with which to affect the patterns of trade and production. Without such parameters one cannot begin to ask the question of whether it would be possible to bring about any Pareto-improvements starting from a position of equilibrium. Nonetheless the optimality properties of the model are of interest because of their implications for the frequently discussed issue of whether the natural rate of unemployment is optimal.

In order to investigate these optimality properties suppose that the government has some instruments. In particular, suppose that a social planner could costlessly take over the hiring decisions of each firm and make unlimited lump-sum transfers between all workers and firms. Then social efficiency would require the hiring rate of each firm to be set so as to maximize the expected present value of output net of the disutility of 
labor, the cost of recruiting, and the cost of search. Suppose, as before, that all workers who have made a contact work until relocation, and all unemployed workers search. (Either the government can force this behavior on workers or the transfer scheme is designed (1ike the wage contract (8)) to induce the behavior.) Then the socially optimal rate of hiring must solve the stochastic dynamic problem with the Lagrangean:

$$
\begin{gathered}
E_{t}^{j} \hat{\mathcal{L} \equiv E_{t}^{j}} \sum_{i=0}^{\infty} \beta^{i}\left\{\left[\pi_{t+i}^{j} f-\underline{w}\right] n_{t+i}^{j}-(G / 2)\left(\hat{h}_{t+i}^{j}\right)^{2} /\left(L-F n_{t+i}^{j}\right)-\frac{1}{F} \sigma\left(L-F n_{t+i}^{j}\right)\right. \\
\left.+\hat{\lambda}_{t+i}^{j}\left[\hat{h}_{t+i}^{j}+n_{t+i}^{j}-n_{t+i+1}^{j} /(1-\delta)\right]\right\}
\end{gathered}
$$

where each Lagrangean multiplier $\hat{\lambda}_{t+i}^{j}$ can be interpreted as the expected marginal social benefit from hiring.

In order to compare the socially optimal rate of hiring with the laissez-faire equilibrium rate, note that the latter solves the problem with the Lagrangean:

$$
\begin{gathered}
E_{t}^{j} \mathcal{L} \equiv E_{t}^{j} \sum_{i=0}^{\infty} \beta^{i}\left\{\left[\pi_{t+i}^{j} f-w_{t+i}^{j}\right] n_{t+i}^{j}-(G / 2) h_{t+i}^{j} / U_{t}^{j}+\lambda_{t+i}^{j}\left[h_{t+i}^{j}+n_{t+i}^{j}\right.\right. \\
\left.\left.-n_{t+i+1}^{j} /(1-\delta)\right]\right\},
\end{gathered}
$$

where $U_{t}^{j}$ is taken as given by (14) and (43).

There are two differences between these two problems (other than the presence of the irrelevant fixed $\operatorname{cost} \Sigma \beta^{i} \sigma L / F$ in the social problem). The first is that the social problem takes into account the fact that hiring today will reduce unemployment in the future and hence will raise the cost of hiring in the future, whereas the private problem, by taking unemployment as given, ignores that effect. For this reason the private firm will tend to hire too rapidly given any existing amount of unemployment. This is a consequence 
of the external diseconomy pointed out in Section 4. In laissez faire no firm sees itself as having any influence on the future size of the commonproperty resource consisting of the pool of unemployed; hence all firms tend to draw upon it more rapidly than if the social depletion cost had to be paid on each hire.

The other difference is that the social problem takes into account the full social gain from a contact:

$$
\partial \hat{\mathscr{L}} / \partial \mathrm{n}_{t+i}^{j}=\beta^{i}\left(\pi_{t+i}^{j} \mathbf{f}-\underline{w}+\sigma\right),
$$

whereas the private problem takes into account only that part of the gain accruing to the firm:

$$
\partial \mathscr{L} / \partial n_{t+i}^{j}=\beta^{i}\left(\pi_{t+i}^{j} f-w_{t+i}^{j}\right)<\partial \hat{\mathscr{Z}} / \partial n_{t+i}^{j}
$$

Only if the wage were equal to the social cost of a contact, $\underline{w}-\sigma$, would a firm in laissez faire be able to capture all the social gains from its marginal hiring decisions. But because this would fall short of the worker's reservation wage it cannot be the equilibrium wage, and hence the firm must share some of the social gain with the worker. For this reason the firm tends to hire too 1ittle, given any existing amount of employment. 5

Because of these distortions the laissez-faire solution will not generally be optimal. But because the distortions conflict the laissez-faire rate of hiring may be either more or less than the socially optimal rate. To be more precise, consider the limiting case in which there are no shocks to relative prices or to aggregate demand $\left(\pi_{t}^{j} \equiv 1\right.$ and $\left.m_{t} \equiv 0\right)$. The Euler conditions of the social problems imply:

$$
\hat{h}_{t}^{j}=G^{-1}\left(I-F n_{t}^{j}\right) \hat{\lambda}_{t}^{j}
$$


and :

$$
\mathrm{E}_{t}^{j}\left\{\pi_{t+1}^{j} f-\underline{E}+\sigma-(F G / 2)\left(\hat{h}_{t+1}^{j}\right)^{2} /\left(I-F n_{t+1}\right)^{2}+\hat{\lambda}_{t+1}^{j}-\hat{\lambda}_{t+1-1}^{j} / B(1-\delta)\right\}=0
$$

In this limiting case there will exist a steady state to the social problem in which $\lambda_{t} \equiv \hat{\lambda}, \mathbf{n}_{t}^{j} \equiv \hat{n}$, and $\hat{h}_{t}^{j} \equiv \hat{h}$. From (21) and (44):

$$
\hat{\mathbf{n}}=\frac{L \hat{\lambda}}{\left(\frac{\delta}{1-\delta}\right) G+F \hat{\lambda}}, \hat{\mathbf{h}}=\left(\frac{\delta}{1-\delta}\right) \hat{\mathbf{n}} \text {. }
$$

There will also exist a steady state to the laissez faire equilibrium in which $\mathfrak{n}_{t}^{j} \equiv \bar{n}, h_{t}^{j} \equiv \bar{h}$, and $\lambda_{t}^{j} \equiv \bar{\lambda}$. From (21) and (29):

$$
\overline{\mathbf{n}}=\frac{L \bar{\lambda}}{\left(\frac{\delta}{1-\delta}\right) G+F \bar{\lambda}}, \overline{\mathbf{h}}=\left(\frac{\delta}{1-\delta}\right) \bar{n} \text {. }
$$

Therefore both hiring and employment will be more or less than their socially optimal values in the steady state according to whether $\bar{\lambda}$ is greater or less than $\hat{\lambda}$. Imposing stationarity on (45) and using (44) yields:

$$
f-\underline{\underline{F}}+\sigma-(\underline{F} / 2 G) \hat{\lambda}^{2}+\hat{\lambda}-\hat{\lambda} / \beta(1-\delta)=0 \text {. }
$$

Equation (48) has the unique positive solution:

$$
\hat{\lambda}=(G / F)\left([1-1 / \beta(1-\delta)]+\sqrt{[1-1 / \beta(1-\delta)]^{2}+(f-\underline{w}+\sigma) 2 F / G}\right)
$$

Obviously $\bar{\lambda}$ will equal $\hat{\lambda}$ only by chance. That $\bar{\lambda}$ can equal $\hat{\lambda}$ is demonstrated by the case where: 6

$$
\xi=1 / 4, \sigma=1 / 32, F / G=1=f-\underline{T}, \beta(1-\delta)=1 / 2,
$$

which yields: $\bar{\lambda}=\hat{\lambda}=3 / 4$. That $\bar{\lambda}$ can be more or less than $\hat{\lambda}$ is demonstrated by taking the same case and increasing or decreasing $\xi$ slightly, because $\bar{\lambda}$ is negatively affected but $\hat{\lambda}$ unaffected by $\xi$. Therefore the laissez-faire values of hiring and employment can be more or less than socially optimal. By 
the same token, the laissez faire value of the natural rate of unemployment, $1-(F / L) \ddot{n}$, can be less or more than socially optimal.

The result that unemployment can be more or less than optimal is not surprising, given the conflicting results of two papers by Diamond (1981 and 1982b) on that question, since the present paper is built upon Diamond's idea of communication externalities. What is perhaps interesting is that these possibilities can be exhibited by the same model. Even more interesting is that this model is almost identical in its output-price predictions to new classical models which are often thought to represent Pareto-efficient equilibria.

\section{The Aggregate Effects of Relative Prices}

The nonlinearity of this model implies that the properties of the stochastic process generating relative-price shocks will affect output, employment and unemployment in ways not found in linear business-cycle models. In the linear approximation to (26) that yields the Lucas aggregatesupply relationship the variability of relative-price shocks has a positive effect on $\eta$ and hence on the impact upon employment of a monetary shock. But in our nonlinear model this variability also has an effect not found in linear systems. Specifically, it has a negative effect upon the expected level of employment in the ergodic distribution. By (14) this implies that the variability of relative prices has a positive effect upon the natural rate of unemployment: $E u_{t} \equiv 1-(F / J L) E n_{t} \cdot$

Furthermore, the degree of persistence $\rho$ of relative-price shocks has these same two effects. It affects the initial employment effect of a monetary shock positively and the natural rate of unemployment positively. 
The effect of relative-price variability upon the natural rate of unemployment is similar to, and hence suggests a possible explanation of the empirical finding by Iilien (1982) to the effect that given any history of monetary shocks the expected rate of unemployment is positively affected by the dispersion of hiring-rates across sectors.

The demonstration of these effects is rather involved and tedious, and hence not very instructive. But some intuition for the effect of relative-price variability upon the natural rate of unemployment can be gained by noting its similarity to the effect described by Lipsey (1960) and analyzed further by Archibald (1969) according to which an increase in the dispersion of unemployment across markets shifts the aggregate Phillips curve to the right if the Phillips curve in each market is convex to the origin; i.e., if the absolute effect upon unemployment of a price-shock is positively related to the amount of unemployment. Most of the added complications in the present formulation of this effect arise because of lags, 1.e., because a price shock affects unemployment only next period, and with an absolute effect that is positively related not to next period's rate of unemployment but to this period's : $\left|\frac{\partial u_{t+1}^{j}}{\partial m_{t}}\right|=(F / L) \frac{\partial n_{t+1}^{j}}{\partial m_{t}}=(F / L)(1-\delta) G^{-1}\left(L-F n_{t}^{j}\right) \alpha \eta$ $=(F / G)(1-\delta) u_{t}^{j} \alpha \eta_{0}$ As discussed in Section 5, this non-1inearity arises because of the externality according to which the cost of hiring depends inversely upon the existing amount of unemployment.

The effect of the natural rate of unemployment of the persistence of relative-price shocks can perhaps be understood by noting that an increase in $\rho$ increases the variability of $\lambda_{t}^{j}$ which is the main source of dispersion across sectors of unemployment rates. 
The rest of this section is devoted to demonstrating these effects. First, we make one more assumption:

$$
v_{t}^{j} \text { is distributed symetrically about zero for all } j, t \text {. }
$$

Next, note that $\mathrm{En}_{t}=\mathrm{JEn}_{t}^{j}$ for any $j$, so we need only show the effects on $\mathrm{En}_{t}^{j}$. From (41) and the fact that $E \varepsilon_{t}^{j}=0$ :

(50) $\quad \operatorname{En}_{t}^{j}=\tilde{n}+\sum_{k=2}^{\infty} E \prod_{l=1}^{k-1}\left(a-b e_{t-l}^{j}\right) e_{t-k}^{j}$

By expanding products and using the fact that $E_{t}^{j}=0$ :

$$
\begin{aligned}
& E \prod_{l=1}^{k-1}\left(a-b \varepsilon_{t-l}^{j}\right) \varepsilon_{t-k}^{j}=a^{k-1} E \varepsilon_{t-k}^{j}-a^{k-2} b \sum_{l=1}^{k-1} E e_{t-l}^{j} e_{t-k}^{j}+\cdots \\
& \ldots+a(-b)^{k-2} \sum_{i=1}^{k-1} E\left(\prod_{\substack{l=1 \\
(\ell \neq i)}}^{k-1} e_{t-l}^{j}\right) e_{t-k}^{j}+(b) E\left(\prod_{\ell=1}^{k-1} e_{t-\ell}^{k-1}\right) e_{t-k}^{j} \\
& =\sum_{r=2}^{k} a^{k-r}(-b)^{r-1} \sum_{c \in C(r, k)} E \prod_{l \in c} e_{t-l}^{j} ; k=2,3, \ldots, \infty,
\end{aligned}
$$

where $C(r, k)$ is the set of subsets of the integers $\{1, \ldots, k\}$ containing exactly I elements, all distinct and one of them being $k$. Take any $k \geqq 2$, any $r \in\{2, \ldots, k\}$ and any $c \in C(r, k)$. Then, from (32):

$$
\text { E } \prod_{l \& c} e_{t-l}^{j}=\gamma^{r_{E}} \prod_{\operatorname{lec}}\left(\sum_{i=1}^{\infty} \rho^{i} v_{t-b-i}^{j}+\eta v_{t-l}^{j}+\eta_{m}-l\right)
$$

Because this product is linear in each $\mathrm{m}_{t-\ell}$ we can use (2) to rewrite the above as :

$$
\text { E } \prod_{\operatorname{lec}} e_{t-l}^{j}=\gamma^{r} E \prod_{\operatorname{lec}}\left(\sum_{i=1}^{\infty} \rho^{i} v_{t-\ell-i}^{j}+\eta v_{t-l}^{j}\right) .
$$

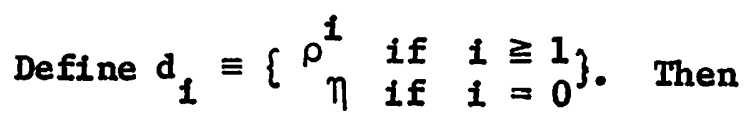




$$
\text { E } \prod_{\ell \in c} e_{t-l}^{j}=\gamma^{x} E \prod_{\ell \in c}\left(\sum_{i=0}^{\infty} d_{i} v_{t-\ell-i}^{j}\right)
$$

Next, we can expand this product to write:

$$
\text { E } \prod_{\operatorname{lec}} e_{t-l}^{j}=\gamma_{1(\cdot) \in I(c)}^{r} \sum_{l \in c}^{E} d_{i(l)} v_{t-b-I(l)}^{j}
$$

where $I(c)$ is the set of all functions mapping $c$ into the non-negative integers. For any such function we have:

$$
\text { E } \prod_{l \in c} L_{i(l)} v_{t-b-i(l)}^{j}=\left(\prod_{l B C} d_{i(l)}\right) \underset{s=1}{r} \mu_{s} \Psi(i(\cdot), r, s)
$$

where $\Psi(i(\cdot), r, 8)$ is a non-negative integer, equal to the number of distinct values of $\phi$ for which $l-1(l)=\phi$ for exactly 8 elements $l$ of $c$, and $\mu_{s}$ is the $s^{\text {th }}$ moment of $v_{t}^{j} \cdot$ (By convention, $0^{\circ}=1$.) Note that

$$
\sum_{8=1}^{r} \Psi(i(\cdot), r, 8)=r
$$

Therefore if $x$ is odd there is at least one odd value of $s$ such that $\Psi(i(\cdot), x, 8) \geqq 1$. But, by (49), $\mu_{8}=0$ for all odd 8 . Therefore

$$
\prod_{8=1}^{r} \mu_{s}^{\Psi(i(\cdot), r, 8)}=0 \text { for all odd } r \text {. }
$$

Therefore, using (50)-(54) we can write

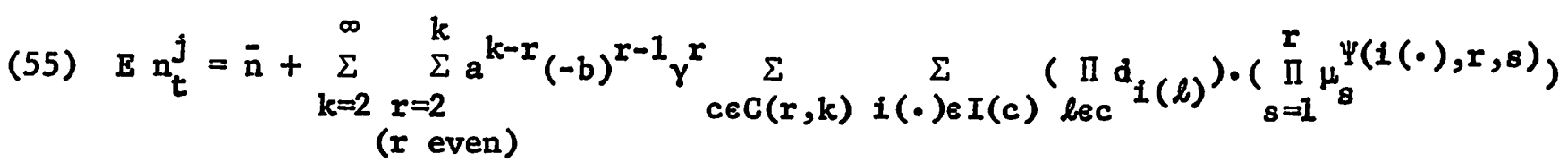

Consider first the effects of an increase in the variability of relativeprice shocks. Specifically, suppose that all the even moments $\mu_{s}$ were to increase. Because $\mu_{2}=\sigma_{v}^{2}$, therefore $\eta$ would also increase. Note that, by $(24)$, (25), $(29),(30),(33)$, and (36), the parameters $a, b$ and $\gamma$ in equation (55) are 
unaffected by this change, as is $d_{i}$ for each $i>0$. So in terms of (55) the change can be represented by an increase in $d_{0}$ and in $\mu_{8}$ for each even 8 . Furthermore, since $a^{k-r}(-b)^{r-1} \gamma^{x}<0$ when $x$ is even, the effect on $\mathrm{En}_{t}^{j}$ will be negative if the effect is non-negative on each of the products of the form (53) and positive on at least one such product. Consider first the effect of the increase in $d_{0}$ on each product. Since $d_{i} \geqq 0$ for all $i$ and $\mu_{8} \geqq 0$ for all $\mathrm{s}$ the effect is non-negative. Next consider the effect of the increase in any $\mu_{s} \cdot$ Since $d_{1}>0$ for all $i, \mu_{s} \geqq 0$ for all $s$, and $\Psi(i(\cdot), r, s) \geqq 0$, therefore the effect is non-negative. Therefore the overall effect on each product is non-negative. Furthermore the effect is strictly positive on each product where $-i(l) \equiv \ell$ and $r$ even, for in such cases the product has the form $\underset{l \in c_{c} l}{(\Pi d)} \mu_{r}>0$.

An increase in the degree of persistence of relative-price shocks, $\rho$, would leave $a, b, d_{0}$, and each $\mu_{s}$ unchanged but would increase $\gamma$ and $d_{i}$ for al1 $i \geqq 1$. The same line of reasoning as above shows that the overall effect on $\mathrm{En}_{t}^{\mathrm{j}}$ of this change is strictly negative.

The effects upon the initial impact of a monetary shock are relatively simple to analyze. From (23) and (26),

$$
\frac{\partial n_{t+1}^{j}}{\partial m_{t}}=(1-\delta) G^{-1}\left(L-F n_{t}^{j}\right) \propto \eta
$$

Given $n_{t}^{j}$ this is increasing in the variability of relative-price shocks which affects $\eta$ positively, and in the degree of persistence of relative-price shocks which affects $\alpha$ positively. Taking expected values of both sides of (56) produces: 


$$
E\left\{\frac{\partial n_{t+1}^{j}}{\partial m_{t}}\right\}=(1-\delta) G^{-1}\left(L-F E n_{t}^{j}\right) \alpha \eta
$$

Thus the expected value of the initial impact of a monetary shock is also increasing in the variability and persistence of relative-price shocks, each of which has not only a positive effect upon the coefficient

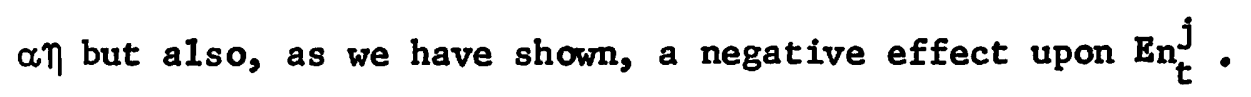




\section{Bibliography}

Archibald, G. Christopher, "The Phillips Curve and the Distribution of Unemployment," Amer. Econ. Rev. 59 (May 1969): 124-34.

Barro, Robert J., "Unanticipated Money Growth and Unemployment in the United States," Amer. Econ. Rev. 67 (March 1977): 101-15.

, "Second Thoughts on Keynesian Economics," Amer. Econ. Rev. Proceedings

69 (May 1979): 54-59.

Diamond, Peter A., "Mobility Costs, Frictional Unemployment, and Efficiency," J. Polit. Econ, 89 (Aug. 1981): 798-812. , "Wage Determination and Efficiency in Search Equilibrium," Rev. Econ. Stud, 49 (Apri1 1982a): 217-27. , "Aggregate Demand Management in Search Equilibrium," J. Polit. Econ, 90 (Oct. 1982b): 881-94.

Granger, C. W. J. and Anderson, A. P., An Introduction to Bilinear Time Series Mode1s. Gottingen: Vanden̨hoeck and Ruprecht, 1978.

Howitt, Peter, "Transaction Costs in the Theory of Unemployment," unpublished, Univ. of Western Ontario, July 1984. and McAfee, R. Preston, "Search, Recruiting, and the Indeterminacy of the Natural Rate of Unemployment," unpublished Univ. of Western Ontario Research Report 8325 (revised), March 1984.

Keynes, J. M., The General Theory of Employment, Interest, and Money. London: Macmillan, 1936.

Laidler, David, "On Say's Law, Money, and the Business Cycle," in his Monetarist Perspectives, Oxford: Philip Allan, 1982.

Ieijonhufvud, Axe1, On Keynesian Economics and the Economics of Keynes. New York: Cambridge University Press. 
Iflien, David M., "Sectoral Shifts and Cyclical Unemployment," J. Polit. Econ. 90 (Aug. 1982): 777-793.

Iipsey, Richard G., "The Relationship Between Unemployment and the Rate of Change of Money Wage Rates in the U.K., 1862-1957," Economica 27 (Feb. 1960): 1-31.

Lucas, Robert E. Jr., "Some International Evidence on Output-Inflation Tradeoffs," Amer. Econ.Rev. 63 (June 1973): 326-34.

Olaun, Arthur Mo, Price and Quantities. Washington: The Brookings Institution, 1981.

Quinn, B. G., "A Note on the Existence of Strictly Stationary Solutions to Bilinear Equations," J. Time Series Analysis 3 (1982): 249-52. Sargent, Thomas J., Macroeconomic Theory. New York: Academic Press, 1979. Treadway, Arthur B॰, "On Rational Entrepreneurial Behavior and the Demand for Investment," Rev。 Econ. Stud. 36 (July 1969) : 227-40. 


\section{Footnotes}

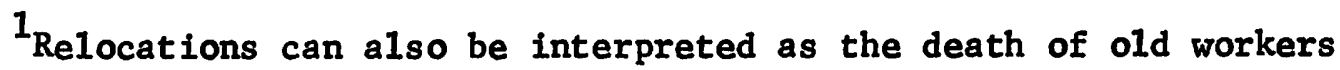
and their replacement by newly born workers. In either case the people who are unemployed in the model will always be the new entrants to their labor market, a prediction which seems roughly consistent with the observed high incidence of unemployment among the young and unskilled.

${ }^{B}$ By (20) and (23) below, $F \theta_{t}^{j}=F G^{-1}\left[\bar{\lambda}+\alpha\left(\rho\left(\pi_{t-1}^{j}-1\right)+\eta\left(v_{t}^{j}+m_{t}\right)\right)\right]$; thus the inequalities (13) can be re-expressed easily, but not instructively, in terms of restrictions on the more primitive variables $v_{t}^{j}$ and $m_{t}$.

3 The alternative formulation: $c_{t}^{j}=(G / 2)\left(\theta_{t}^{j}\right)^{2}$ is perhaps more straightforward and yields almost the same results as (18) except for the results reported in Section 8 on the effects of relative prices, which become not only more complicated but also, as far as I have been able to determine, ambiguous. Note also that according to (18), $c_{t}^{j}=(G / 2)\left(\theta_{t}^{j}\right)^{2} U_{t}^{j}$. Thus if $\theta_{t}^{j}$ is held constant the cost of recruiting is increasing in $U_{t}^{j}$ because as $U_{t}^{j}$ goes up the number hired will increase. Thus the negative effect that we are discussing of unemployment upon recruiting costs supposes that $h_{t}^{j}$ is held constant, not $\theta_{t}^{j}$

${ }^{4}$ Involuntary unemployment also exists in the sense of Keynes (1936, p. 15). If the price level were to rise (because of a monetary shock) and the money wage contract did not adjust (i.e., if the real wage in each contingency were reduced equi-proportionately) then both firms and workers in each market would want the rate of hiring to be greater than what it would have been in the absence of that exogenous change. 
${ }^{5}$ similar result was found in the context of a closely related labormarket mode1 by Diamond (1982a).

${ }^{6}$ Note that this case also satisfies the inequalities (9), (13), and (15) for $x_{1}=1, x_{2}=3 / 4, x_{3}=1 / 4$. 